\title{
Política social en Europa: el juego de las apariencias
}

\section{Fernando Casas Mínguez *}

\section{Introducción}

En esta exposición reflexiono sobre el replanteamiento de las políticas sociales europeas, en estos momentos de cambio y adaptación de las políticas de los Estados a las nuevas condiciones, definidas como de globalización económica y competencia internacional. Por su estrecha relación con el asunto comienzo especulando sobre las orientaciones políticas en materia de empleo, para continuar con el análisis de la propuesta conocida como "pluralismo del bienestar" o, más concretamente, la versión neoliberal de esa opción que es la ideología que viene impregnando, a mi juicio, las orientaciones actuales en materia de política social.

Mi cometido, al redactar estas líneas, ha sido doble. De una parte, poner de relieve las debilidades teóricas del empobrecido modelo económico dominante, consagrado a la competitividad y el crecimiento, que tienen su reflejo emotivo en las apelaciones a valores humanitarios, la moral, y la solidaridad. De otra, expresar mi inquietud sobre la idoneidad de las fórmulas voluntaristas y filantrópicas, propugnadas como solución para reparar los problemas producidos por nuestra economía globalizada.

No descarto la posibilidad de que tan desconcertante y generalizada apelación a valores morales y humanitarios pueda acabar socavando los implacables principios que todavía rigen en una ciencia tan lúgubre como la economía (CARLYLE). Pero tengo serias reservas sobre la validez de recetas afines con las tendencias filantrópicas del siglo XIX, para remendar problemas del siglo XXI.

\section{Olvido del empleo}

"Lo asombroso respecto al destino de millones de jóvenes mal pagados y subempleados sin futuro es la indiferencia de la sociedad, incluyendo la indiferencia de la clase media progresistan. J. PETRAS.

El Estado de bienestar de posguerra, que consiguió hacer el capitalismo económicamente más productivo y socialmente más justo, reposaba en dos pilares. El uno, keynesiano, según el cual el Estado intervenía desde la demanda para asegurar la actividad económica y el pleno empleo. El otro, beveridgiano, en virtud del cual el Estado se encargaba de la provisión pública de servicios sociales de carácter universal (rentas mínimas, sanidad, educación, vivienda y servicios sociales personales).

El impacto de la crisis, el acceso al poder de gobiemos liberales, y la victoriza ideológica del neoliberalismo, pusieron fin a ese "capitalismo dirigido con sensatez" '. Lo primero que se desquició fue el empleo: los gobiernos de la mayoría de los países fueron abandonando el pleno empleo como objetivo nacional. Ciertamente, los ciudadanos de los países europeos vienen considerando la lucha contra el paro como uno de los objetivos prioritarios del programa de actuación de los poderes públicos; pero están lejos de compartir este planteamiento - salvo en los períodos de elecciones-, los dirigentes europeos, y quienes controlan el intrincado mundo financiero y empresarial de nuestra economía globalizada.

Partiendo de la definición del problema del paro en términos de rigideces del mercado laboral, y altos costes sociales, pero guardando un espeso silencio sobre todo lo relacionado 
con la reducción de jornada y reparto de beneficios, los responsables políticos europeos han tendido, con sus decisiones, (por ejemplo, las actuaciones relacionadas con la reforma de la legislación laboral, o el modelo de construcción europea diseñado en Maastricht, que excluye la tasa de paro entre los criterios de convergencia) ${ }^{2}$, a favorecer lo que denominan, eufemísticamente, flexibilización del mercado laboral; y decidieron no adoptar medidas diseñadas como lenitivos para mitigar el sufrimiento de las politicas de rigor de Maastricht: vetando las propuestas sobre empleo previstas en el Libro Blanco de Delors ${ }^{3}$ (redes de transporte europeo), impidiendo la aplicación a proyectos generadores de empleo de la mitad de los ahorros presupuestarios previstos de 1997 a $1999^{4}$, negando la dotación de recursos al Pacto Europeo de Confianza para el Empleo, (acaeció el verano del año 1996 en el Consejo Europeo de Florencia y algo semejante sucedió el mes de junio de 1997 en Amsterdam) ?. Las políticas adoptadas por nuestros dirigentes implicaban no ofrecer una respuesta adecuada a los 18,1 millones de ciudadanos de la Unión Europea que estaban sin empleo.

El Parlamento Europeo, sensible hacia este grave problema, encargó un estudio para medir el previsible impacto de Maastricht sobre el empleo. De acuerdo con el Informe elaborado por expertos economistas, los objetivos de convergencia podian costar 1,5 millones de puestos de trabajo en la Unión Europea. Según los autores del mencionado estudio, si se aplicaran políticas fiscales expansivas y políticas monetarias más relajadas se podrían crear más de 2,2 millones de empleos de los previstos ${ }^{6}$.

No obstante, quienes desde su posición de poder han venido definiendo la realidad siguen empenados en presentar las políticas de rigor presupuestario como el remedio eficaz para la lucha contra el paro. En este sentido se expresó el primer presidente del Instituto Monetario Europeo, el belga Alexandre Lamfalussy, en su discurso de despedida. Después de afirmar que «el crecimiento económico repercute favorablemente sobre el empleo", señaló la necesidad de eliminar "el componente estructural -y por tanto más importante- del desempleo (...) con medidas que contrarrestren la rigidez de los mercados laborales y que reduzcan los costes salarialesn?

La afirmación y propuesta contenidas en el discurso de Lamfalussy requieren un breve comentario. Su aserto sobre la correlación entre crecimiento y empleo resulta problemático. Conviene no olvidar al respecto la reflexión de los autores del llamado Libro Blanco sobre el empleo, a saber: España y Alemania con ritmos de crecimiento comparables durante quince años, en torno al 2,3\%, contaban sin embargo con niveles medios de desempleo del $16 \%$ y el $6 \%$, respectivamente. De otra parte, insistir a estas alturas en los argumentos de las rigideces constituye un exceso. Podía haber sugerido la necesidad de impulsar otras medidas, como el impuesto sobre la energía $\mathrm{CO} 2$, o la imposición homogénea, en origen, de la rentas del capital fi- nanciero, cuya cuantía permitiría desarrollar políticas para combatir simultáneamente el desempleo y la contaminación.

Distinta es la percepción que sobre el paro tienen los dirigentes del mundo de los negocios. En principio es palpable que ellos no definen el paro como problema, de la misma manera que lo hacen la mayoría de los ciudadanos. Uno llega, sin mucho esfuerzo, a esta incómoda conclusión cuando comprueba que el anuncio de creación de nuevos empleos puede provocar estrepitosas caídas en las Bolsas. La sorprendente noticia, que apareció en titulares de prensa durante el mes de abril del año 1996 decía así: "La creación de empleo provoca una fuerte caída de Wall Street" ${ }^{8}$. En efecto, por esas fechas la Bolsa de Nueva York padeció un temido crash, parecido al de 1987, cuando se anunció por el Departamento de Trabajo que se habian creado 140.000 nuevos empleos. Y esta reacción tuvo lugar durante algunos meses ${ }^{9}$ motivada, sin duda, por la preocupación de que una acelerada creación de empleo ocasionara un aumento de inflación y los tipos de interés ${ }^{10}$. Durante el año siguiente pudimos asistir al proceso inverso: una subida de 100 puntos a media sesión para celebrar el ascenso del paro en el mes de junio ${ }^{11}$.

Esta actitud ante el empleo no significa, en modo alguno, que entre los representantes del mundo de los negocios estén ausentes las consideraciones morales a la hora de diseñar sus políticas. Más bien lo que pone de relieve es que sus dilemas son otros. Están muy preocupados, por ejemplo, en los sobornos de empresas ${ }^{12}$ o Gobiemos para conseguir contratos internacionales que, según los cálculos, han hecho perder a las empresas estadounidenses más de 45.000 millones de dólares (6'52 billones de pesetas); razón por la cual, Washington ha impulsado un acuerdo antisoborno internacional que, a instancias del grupo de presión Transparencia Intemacional, fue aprobado por los países de la OCDE en París ${ }^{13}$.

También les viene preocupando muy seriamente, a conocidas compañias multinacionales, las operaciones económicas llevadas a cabo por empresas dedicadas a la gestión de los fondos de pensiones. Los gestores de esas empresas, considerados como los nuevos corsarios del mundo de los negocios, consiguen mediante el manejo despiadado de capitales ajenos, amasar enormes fortunas, aunque ello sea a costa de poner en peligro la capacidad productiva de compañías importantes. Sus operaciones, de adquisición hostil o compra forzada de empresas, con fines especulativos, han provocado la decadencia de unas, la desaparición de otras y, en ocasiones, han llegado a constituir una amenaza para la economía de países poderosos. Por este motivo, algunos representantes de las élites económicas, después de las imprevistas turbulencias económicas de los 80 , han propuesto la necesidad de algunas regulaciones en los mercados. En este sentido, argumentan que una sociedad democrática no puede tolerar la subordinación de todas sus metas y prioridades a los beneficios inmediatos de unos cuantos accionistas. 
Sin embargo, conviene no llamarse a engaño, una cosa es el repudio formal de aspectos de este capitalismo especulador y solicitar las correspondientes intervenciones, para preservar mejor el comercio internacional y el fururo económico, a largo plazo, de los Estados Unidos y de ela libre empresa. ${ }^{14}$ o demandar que se tipifique como delito el pago de comisiones que periudican a empresas americanas; y otra, bien distinta, proceder a un debate a fondo sobre un modelo de desarrollo que además de reposar en la comupción ${ }^{15}$ y la especulación, se caracteriza por una utilización insuficiente del trabajo y por la sobreexplotación de recursos naturales.

En resumen, la opción que domina en nuestra economía globalizada, en la práctica, es la de ahorro en mano de obra, si es necesario recurriendo a formas más o menos encubiertas de despido, con vistas al aumento de productividad de las empresas, para conseguir una mayor competitividad. El riesgo que entraña la opción de crecimiento escogida es que quede neutralizado el ahorro por el aumento de costes para la colectividad ${ }^{16}$, (bajo la forma de subsidios de desempleo, pensiones de jubilación anticipada, ingresos fiscales no recaudados, y mayores cargas sociales debido al aumento de la pobreza, delincuencia y deterioro de la salud), con el consiguiente efecto perverso de pérdida de la competitividad. Se crearía así una especie de círculo vicioso, que podría acabar induciendo, de nuevo, a políticas de reducción de plantilla, traslados de empresas, o a la economía sumergida ${ }^{17}$.

Es posible concluir, por tanto, que el deseo de los miembros de la Comisión de las Comunidades Europeas, redactores del denominado Libro Blanco, de alcanzar una sintesis razonable entre las metas perseguidas por nuestras sociedades: trabajo, y las exigencias de la economía: competitividad, no constituye un objetivo ampliamente asumido ${ }^{18}$. Como hemos intentado probar, han discrepado de esta recomendación las élites del mundo de los negocios, que lideran este capitalismo de casino sin reglas en que vivimos, y la mayoría de los Jefes de Estado y Gobierno europeos ${ }^{19}$, con independencia del color político de quienes eventualmente asistieran a las cumbres. La propuesta que viene obteniendo en la práctica una aceptación abrumadora es la que recomienda insistentemente los Estados Unidos: "restaurar los equilibrios presupuestarios, (...) profundizar las reformas económicas que reduzcan las barreras (entiéndase: rigideces y prestaciones sociales) a la creación de empleo" ${ }^{20}$.

\section{Centralidad de la política social}

"Los gastos del Gobierno sólo se convierten en cargas cuando favorecen a los más pobres". J.K GaLbrar'H.
Respecto al otro fundamento del Estado de bienestar, los servicios sociales universales, si la amenaza de su desmantelamiento no se ha llevado a cabo es debido, en parte, a los riesgos electorales que comportaha, y también porque las políticas sociales están siendo instrumentalizadas para facilitar la transición de los sistemas productivos. En este sentido, llama la atención cómo, en abierta contradicción con la retórica de los discursos - en los que se arremete contra las políticas sociales por su alto coste y sus efectos perversos-, gobiernos de distinto signo político, incluso los empapados en doctrina neoliberal, están utilizando los sistemas de protección social como instrumentos de racionalización y reestructuración de las empresas privadas. Buen ejemplo de ello lo constituyen las políticas de jubilación anticipada ${ }^{21}$ alentadas o consentidas por los gobiernos, que están teniendo lugar en distintos países en estos tiempos de crecimiento sin puestos de trabajo. En nuestro país, desdichadamente, estas políticas relacionadas con el fomento del empleo han tenido un "coste extraordinario y unos resultados nefastos". El método ha permitido a las empresas transferir a las arcas de la Seguridad Social gran parte de los costes de reestructuración ${ }^{22}$.

Es innegable que el Estado de bienestar en plena crisis ha continuado desempeñando un importante papel en el mercado de trabajo: facilitando la salida de las personas mayores, mediante la jubilación anticipada; manteniendo la demanda laboral, cuando crea puestos de trabajo en sanidad, educación y protección social; facilitando el trabajo de la mujer, cuando proporciona los servicios sociales necesarios y, en fin, ayudando a que las personas hagan compatible su papel de trabajador, con el de ciudadano y miembro de una familia, al proporcionar a los trabajadores vacaciones pagadas y ausencias temporales del trabajo ${ }^{23}$.

Lo que resulta en verdad pasmoso es contemplar cómo los apologetas de la reducción del tamaño del Estado y la no intervención ${ }^{24}$ están dispuestos a financiar, con cargo a los presupuestos públicos, la competitividad y modernización de empresas ${ }^{25}$ para, acto seguido, pronunciar sin inmutarse alegatos contra esas mismas políticas porque producen déficits presupuestarios. $\mathrm{Si}$ en el desconcertante nuevo orden mundial en que vivimos admitimos que es apropiado utilizar la política social, de forma inmediata, para costear objetivos inicialmente no previstos -como la modernización-, en provecho de la empresa privada (animar a ciudadanos en edad y condiciones de trabajar a que abandonen su empleo), se entiende mal que sean desdeñadas, por gravosas, las medidas de protección social adoptadas para atender precisamente los previsibles efectos colaterales que acarrean esas modernizaciones. Constituye un contrasentido que quienes sacan provecho de las costosas medidas de protección social para ordenar el mercado de trabajo se despachen con discursos incendiarios contra esas mismas políticas. 
Ciertamente estas actuaciones dan lugar al inevitable problema del déficit presupuestario. Pero como señalan, sagazmente, los autores del Libro Blanco sobre el empleo ${ }^{26}$, se podrían reducir los déficit presupuestarios ${ }^{27}$ y compensar las políticas encaminadas a la reducción de costes laborales (impuestos y cotizaciones), mediante medidas como los impuestos medioambientales ( $\mathrm{CO} 2$ ), impuestos sobre la fiscalidad del capital, o sobre el consumo de productos nocivos para la salud. Los sustanciosos ingresos del aimpuesto $\mathrm{CO}_{2}{ }^{28},(1 \%$ del PIB), que cuenta con un importante apoyo popular, permitiría combatir a un tiempo el desempleo y la contaminación medioambiental, y fomentaría un nuevo modelo de desarrollo basado en mayor uso del empleo y un menor consumo de energía. Mientras este otro modelo de desarrollo no cuente con el apoyo de grupos sociales poderosos, las políticas social y de empleo tenderán a seguir subordinadas, de momento, a la política económica.

Quizá debido a esta instrumentalización de los sistemas de protección social, es decir, de la función primordial que la política social ha pasado a desempeñar en provecho de la actual modernización económica, estamos asistiendo a un fenómeno paradójico. Me refiero al hecho de que en plena crisis y cambio del escenario político, demográfico, tecnológico y financiero, el papel asignado por gobiernos y organismos internacionales a las políticas sociales continúa, en apariencia, siendo central. Reflexionar sobre los rasgos de este contradictorio planteamiento y su actual influjo en Europa será el objeto del siguiente epígrafe.

\section{Pluralismo del bienestar}

"El hincapié en el voluntariado comunitario y la caridad como sustitutos del Estado de bienestar, aunque refuerza la importancia de una sociedad civil solidaria, es sobre todo una pantalla ideológica para no afrontar el abandono cínico de una responsabilidad colectiva con el pretexto de ejercer la responsabilidad individual. M. CASTELLS.

En principio, es preciso comenzar recordando que, desde la perspectiva del neoliberalismo dominante, la política social tiende a ser considerada como una pesada carga: a mayor políica social más problemas" ${ }^{20}$. Aunque en esta coyuntura, y por las razones pragmáticas y estratégicas apuntadas, este "pesado lastre. que arrastran los Estados de bienestar, haya pasado a ser valorado como un elemento necesario y positivo, porque puede favorecer el crecimiento, la competitividad y el empleo. Paradójicamente, los partidarios del Estado keynesiano, ante la imposibilidad de defender el modelo de protección del Estado de bienestar y la necesidad de salir al paso a la consabida retórica neoliberal de desmantelamiento ${ }^{30}$, defenderán nuevas orienta- ciones sobre política social que casualmente coinciden con los planteamientos neoliberales.

Esta feliz coincidencia ha propiciado el diseño de formas de protección social acordes con la definición elaborada sobre la realidad, de crecimiento sin empleo ${ }^{31}$ y globalización, articuladas en torno a nuevas combinaciones entre lo público y lo privado, que persiguen mayor eficiencia, menor dependencia y que, además de ser aceptadas socialmente, permitan alcanzar mayor justicia. Un reflejo de este mágico planteamiento, (en el que todo lo bueno va junto), lo hallamos en las políticas que propugnan las autoridades europeas, inspiradas por el denominado "pluralismo del bienestar* ${ }^{32}$.

Conviene tener muy presente que bajo este ambiguo rótulo de provisión mixta de bienestar se puede estar haciendo referencia a cosas cualitativamente diferentes. De una parte, a la modalidad descentralizadora y participativa que, con sus iniciativas innovadoras, corrige y completa las políticas de intervención estatal. Los partidarios de esta opción radical están preocupados porque los sistemas de protección social funcionen de forma más ágil. Les interesa el problema de los costes y la eficiencia, pero sobre todo conseguir que los profesionales de los servicios de bienestar recuperen el sentido humano de lo social y sean respetuosos con los derechos de los ciudadanos. Desconfían de las fórmulas estatistas, burocráticas y tecnocráticas como respuesta a los problemas sociales $y$, a la postre, persiguen la politización de la sociedad. Su propuesta está ligada a una redefinición de la política y a una nueva concepción de la sociedad, la democracia y la libertad. Opinan que la democracia no puede seguir siendo asimilada exclusivamente a la competencia por los votos. Además de elección de los gobernantes, significa limitación del poder y representación auténtica de los intereses sociales, esto es, satisfacer las demandas de la población que reclama capacidad de autonomía para gestionar sus vidas y no quedar abandonado y aplastado. La propuesta, en palabras de A. Tourane, consiste en reivindicar la noción de sujeto, lo que implica abandonar la ideología paralizante de la impotencia alo mejor que se puede hacer", que se concreta en la "democracia sin política" ${ }^{33}$.

Pero la expresión de "pluralismo de bienestar", también designa la estrategia diseñada para desplazar al "gravoso, sobrecargado e ineficiente $e^{\text {Estado de bienestar }}{ }^{34}$, y construida con el designio neoliberal de reducir su tamaño y aligerar los costes en protección social. Postula transformar el Estado de bienestar, es decir, que reduzca sus gastos de regulación a la mínima expresión; en materia de pensiones y sanidad, que suncione con criterios de capitalización", en fin que el Estado se retire y udevuelva a la iniciativa privada lo que ésta le ha cedidon. Este enfoque esencialista del Estado comparte con el anterior un planteamiento analítico importante: ambos estiman que no es posible hacer frente y resolver, con éxito, por medio de la intervención estatal, los conflictos, contradiccioncs y problemas que tiene ante sí la nue- 
va sociedad. No obstante este acuerdo inicial, las orientaciones políticas son divergentes; el proyecto neoliberal trata de restaurar los fundamentos no políticos de la sociedad civil (propiedad, mercado, familia, trabajo, ciencia) y reprivatizar los conflictos y tensiones que no se manejan bien desde el Estado, con el objeto de salvaguardar la autoridad ${ }^{35}$; mientras que el planteamiento radical, como vimos, trataba de politizar las instituciones de la sociedad civil, reconstituyendo una sociedad que ya no depende tanto del Estado.

En este capitalismo de casino sin reglas, en el que nos ha tocado vivir, imaginar que la política social, que propugnan los pragmáticos dirigentes políticos y económicos de la Europa de Maastricht, esté inspirada en el modelo de pluralismo participativo e innovador, cuyo resultado eventualmente fuese la politización de la sociedad civil, sería un desatino. Por el contrario, todo apunta a que la versión pluralista en boga lejos de ser la opción conocida como "bienestar mixton de orientación radical, se acerque más bien a la propuestas de los neoliberales. Sus postulados han ido silenciosamente arraigando entre nosotros al compás de la crisis, y a medida que nos aproximábamos al establecimiento del mercado único, debido al doble miedo a la competencia desleal y al "turismo social" ". Y es posible sostener que el éxito de la opción neoliberal está siendo innegable, al menos mientras las prioridades de la agenda política europea continúen siendo reducir el déficit, la deuda y la inflación, y la feliz noticia de un aumento notable del empleo, al poner en peligro la sagrada tasa de inflación, provoque estrepitosas caidas en las Bolsas.

Sin duda puede haber influido en la hegemonía de esa opción no tanto el proceso de mundialización económica, sino el más abrumador de universalización de valores y políticas. Ambos fenómenos, expresión de la apoteósis ideológica neoliberal en que estamos sumidos, han contribuido a que todos tengamos que comulgar con idénticos objetivos: la competitividad, debamos aceptar parecido interés: el crecimiento, y acabemos asumiendo la subordinación de la política social a objetivos estrictamente económicos. Si las consideraciones anteriores son correctas, podríamos concluir senalando que, en estos tiempos de repliegue del keynesianismo y predominio del denominado "pensamiento único", el "pluralismo de bienestar" con ascendiente en los USA es la forma que reviste hoy el neoliberalismo para hacerse presentable en sociedad.

En efecto, basta un superficial examen para comprohar el estrecho parentesco de esta modalidad de pluralismo con los discursos sobre "el retorno de la sociedad civil" ${ }^{37}$, que vienen propugnando, desde hace algún tiempo, quienes después de afirmar que el Estado se ha vuelto pequeño para los grandes problemas de la vida (turbulencias monetarias), y grande para los pequeños (bienestar social y medio ambiente), demandan la vuelta a una escala manejable de la vida social, haciendo hincapié en las organizaciones voluntarias, empresas, iglesias, comu- nidades plurales, etc. Los renombrados defensores de este modelo pluralista consideran que, frente al equitarle dificultad a las cosas. (los problemas de jubilación, desempleo, criar hijos sin padre), auna buena política social debe animar a crear afiliaciones jugosas, impregnadas de responsabilidad y esfuerzo, usadas como modos de vivir de acuerdo con las propias creencias. Esta vuelta a la gente, frente a la earrogante impertinencia de la Administración, serviría para dar su turno al mercado, reanimar la familia y aliviar el problema de sobrecarga.

El encantador cuadro que nos suelen presentar los valedores de este "pluralismo del bienestar, cuando teorizan sobre la sutil estructura de la sociedad y sus benéficas estructuras mediadoras, no debe hacernos olvidar el pasado ni ignorar el presente. En relación al pasado, conviene recordar que sin el histórico fracaso del mercado y de las admirables organizaciones voluntarias, el Estado nunca hubiera adquirido, posiblemente, tanto protagonismo. Sin embargo, muchos de los mordaces críticos del Estado del bienestar, por la misma razón que se resisten con destreza a valorar sus éxitos, prestan poca atención a este aspecto del pasado. Y sobre el presente, por más que nos empeñemos en envolver con velos emotivos y sentimentales la dura realidad económica, los datos se alzan ante nosotros para recordarnos el precio que tenemos que pagar por nuestras reorientaciones políticas.

No deja de ser elocuente lo que está sucediendo a este respecto en Norteamérica, —rezagada en política social" pero, según suele decirse, adelantada en cuanto a derechos donde la herencia del voluntariado, que impulsó Reagan y remató Bush con su poético plan de caridad "Mil puntos de luz" ${ }^{39}$, ha sido recogida entusiásticamente por Clinton.

Decidido a achicar lo que le queda del Estado de bienestar, el presidente Clinton trató de afrontar con el voluntariado el problema de los 15 millones de jóvenes de la opulenta América, que viven en la pobreza expuestos al crimen y la droga. Para lo cual promovió en Filadelfia, durante el mes de abril de 1997, una "Cumbre sobre el futuro de América. Sus sesiones, presididas por el famoso general Colin Powell (un conservador fiscal con conciencia social.), estuvieron especialmente dirigidas a la seducción de las grandes empresas para que incrementen sus escasas donaciones de dinero ${ }^{40}$, aunque aprovecharon la ocasión para hacer un llamamiento a los ciudadanos pidiéndoles más recursos económicos, y que dediquen su tiempo y compromiso a las organizaciones voluntarias. En esa magna concentración, a la que además de Clinton asistieron los ex-presidentes Ford, Carter y Bush, se presentó un plan para "salvar a dos millones" de los 15 millones de jóvenes excluidos ${ }^{41}$.

A pesar del ostentoso prestigio que otorga ser millonario filántropo, de las ventajas fiscales que proporciona, de su utilidad probada para encubrir fechorías ${ }^{42}$ y de su uso como estrategia de marketing por las empresas (productoras de ordenadores, hela- 
dos, refrescos, leches o gafas), los propios ricos han denunciado la tacañería y falta de generosidad de sus pares. Por tanto, la estrategia alentada por Reagan, de voluntariado combinado con filantropía, ha contribuido al recorte de gastos sociales, pero hay serias dudas sobre su eficacia.

Sobre las consecuencias últimas de la estrategia merece la pena recordar lo que WACQUANT nos relataba no hace mucho. Describía el proceso que venía teniendo lugar en los Estados Unidos, de sustitución progresiva del Estado de bienestar residual, por otro Estado que él denominaba "penal y policial. A medida que las desigualdades y la inseguridad económica han ido aumentando, apuntaba WACQUANT, el Estado ha ido recortando competencias y presupuestos. Los programas de guerra contra la pobreza han cedido el paso a la guerra contra los pobres. Y esa proceso que culminó con la Ley Clinton, del verano de $1996^{\text {i3 }}$, poniendo a la miseria fuera de la ley, utiliza como recurso sistemático el encarcelamiento. Los resultados no se han hecho esperar, en diez años se ha duplicado la población reclusa y en el año 1997 el 12,5\% de la población adulta, en torno a los cinco millones de estaclounidenses, se encontraba bajo tutela penal ${ }^{44}$.

La versión europea de este planteamiento es, por suerte, más suave y mucho menos policial, gracias a las particularidades del modelo social y político del viejo continente. Apareció recogida en el denominado Libro Blanco sobre el empleo, y se concreta, de un lado, en la recomendación de renovar el modelo de sociedad, lo que significa crear una nueva asociedad activada por ciudadanos conscientes de sus propias responsabilidades y animados por el espiritu de solidaridad"; por otro, según palabras de los autores del citado estudio, en un replanteamiento de la protección social para mejorar su eficacia y aligerar sus costes, apelando a una mayor responsabilidad y selectividadn; y todo ello, con el objetivo de mantener la cohesión y una economía de mercado competitiva.

Las recomendaciones del borrador del Libro Blanco dirigidas a impulsar el mercado y el librecambio sin límites, dicho sea en honor de la verdad, vienen comiendo mejor suerte que otras propuestas, también contempladas por el documento, para el mantenimiento del Estado de bienestar (como el impuesto sobre contaminación y las medidas políticas, de corte keynesiano, para la creación de 15 millones de empleos), que los ministros de Economía y Finanzas de la Unión Europea decidieron eliminar ${ }^{45}$.

Las propuestas de desguace del Estado de bienestar, además de recurrir a los números (es un reconte indispensable para que salgan las cuentas), suelen acudir, sin el menor empacho, a la lógica argumental que utilizan los ecologistas "no podemos cometer la crueldad de entregar un sistema en quiebra a nuestros hijosn. De esta manera, la retórica neoliberal, insaciable, encubre sus ideológicos mensajes con apelaciones a la ética intergeneracional ${ }^{46}$.
Esta retórica y las políticas correspondientes se comprenden mejor cuando se acepta, aunque resulte incómodo, que la construcción europea, diseñada en Maastricht, reposa en objetivos financieros y monetarios ${ }^{47}$, y a sus artífices les importó un bledo la política social. Los países europeos sólo incluyen este tema en sus agendas cuando amenazan aquellos objetivos en períodos electorales ${ }^{48} \mathrm{y}$, patéticamente, para envolver con justificaciones morales ("evitar la explotación inmoral de mujeres y niñosn), sus injustas políticas proteccionistas frente a los tomates del Magreb, los tejidos de Taiwan, las bicicletas de China, los mariscos de Birmania o los plátanos procedentes de Centroamérica ${ }^{49}$.

Es posible afirmar, por tanto, que los actores y fuerzas sociales interesados en impulsar la acumulación y frenar las políticas de reforma están utilizando, en esta fase de transición, la estrategia del "pluralismo de bienestar" para impregnar y controlar la agenda de política de los Estados de bienestar, y pretenden ir impulsando políticas consistentes en preparar las condiciones (ideológicas, sociales y políticas) que, sin prisa pero sin pausa, favorezcan el desmantelamiento progresivo y sin concesiones de los logros que quedan de ese modelo de Estado.

La validez de esta estrategia para responder a los problemas que tiene planteados nuestras sociedades es dudosa, su utilidad para enmascarar el propósito de adelgazamiento del Estado innegable. Las dudas no provienen de simples prejuicios o razones de tipo ideológico, son más bien de carácter lógico. El razonamiento, en esencia, gira en torno a la idea de la inconsistencia de valores. Los valores sobre los que se sustentan los planteamientos del pluralismo (comunidad y solidaridad) no guardan relación con los que regulan el funcionamiento de nuestra sociedad y del sistema económico (individualismo y competitividad). En base al argumento de la inconsistencia, se podría hacer el siguiente razonamiento: en primer lugar es viable y seguramente muy rentable sustituir la política social de los Estados de bienestar por empresas que, a cambio de un precio, ofertan un producto para mejor contribuir a nuestro bienestar social. Sin embargo, y en base al mismo razonamiento, no se puede decir que sea tan fácil lograr que los ciudadanos que han vivido a la sombra de los Estados de bienestar se conviertan en los sucedáneos de la política social.

No es tan sencillo conseguir que los individuos se organicen y asuman como un deber y compromiso moral atender de forma sistemática, y sin obtener beneficio alguno, los problemas producidos por nuestras complejas sociedades. Por razones obvias (crecimiento, competitividad y empleo son los que mandan), hay menos dificultades para reconvertir los programas de política social en una actividad mercantil reconocida, que conseguir que se reintegren en el campo de las actividades no monetarias. Pero como nada es imposible para los dirigentes de esta sociedad de lo espectacular integrado;, debemos estar dispuestos a que nos asombren con su inusitada destreza para convertir lo virtual 
en real. Justo es admitir que también en este terreno la capacidad de nuestros semejantes escapa de lo razonablemente imaginable.

Quienes valoran positivamente este modelo pluralista, que persigue la disminución del papel del Estado en la política social, argumentan con la especie de que se trata de un simple cambio en la forma de producir el bienestar (descentralizada, participativa, privada y plural); y estiman como muy probable que el incremento y la diversificación de la oferta puede aumentar el bienestar total de la sociedad. Pero una oferta diversificada y competitiva cuyas aspiraciones se contraigan a abaratar costes y sanear presupuestos es dudoso que favorezca el bienestar. El caso americano en materia de salud puede servir de advertencia ${ }^{30}$.

Conocemos, por experiencia, lo que pueden dar de sí políticas pluralistas y, desde luego, descentralizadas, como las puestas en práctica por algunas instituciones de nuestro país, en colaboración con renombradas ONG'S (financiera y políticamente dependientes, por cierto, del gobiemo de turno). Me refiero, en concreto, a las pergeñadas para la uprevención y erradicación de la mendicidad" por algún que otro Ayuntamiento en colaboración con la llamada sociedad civil. En su obsesión por la eficacia, seguridad o la estética, se han desentendido de la protección de los pobres y desfavorecidos, y han dirigido sus mejores esfuerzos al propósito exclusivo de hacer invisible la pobreza ${ }^{31}$.

Pero al margen de estas desafortunadas experiencias, cuesta trabajo imaginar de qué forma nuestra compleja y polarizada sociedad pueda dar lugar a esa otra sociedad activada, responsable y solidaria" - Libro Blanco de Delors-, dispuesta a suplir las deficiencias de los sistemas de protección de los Estados ${ }^{52}$ y dedicar lo mejor de sus esfuerzos a la atención de los más desaventajados. La propuesta, seguramente prenada de valores éticos y filantrópicos encomiables, constituye en los tiempos que corren una franca huida de la realidad y, por tanto, no es extraño que provoque cierta inquietud.

\section{El porvenir filantrópico}

"La primera intención de la dominación espectacular era hacer desaparecer el conocimiento histórico en general y, desde luego, la práctica totalidad de las informaciones y los comentarios razonables sobre el pasado más reciente. G.DEBORD.

No es por pregonar el pesimismo, pero cunde la sospecha de que, salvo condición de garantía fundamental de derechos sociales para todos los ciudadanos europeos, la ideología del pluralismo refuerce, en la práctica, la tendencia a la dualización e impulse el control social. En última instancia, el temor es que el actual modelo de Unión Europea traiga consigo un neo-filantropismo supranacional, que impondría el traslado de la elaboración de las políticas sociales desde el Estado a la llamada sociedad civil ${ }^{33}$. Dicho de otra forma: Maastricht y el Pacto de Estabilidad ${ }^{34}$ serían el pretexto para que los dirigentes de los distintos países europeos procedan al derribo controlado de su correspondiente Estado de bienestar y a la restauración del mercado "Salvo que la sociedad inexistente, ${ }^{30}$ se decida a asumir la defensa de una sociedad civilizada.

La primera protesta colectiva contra ese modelo de construcción europea, elitista y sobre los escombros del Estado de bienestar, se realizó por los ciudadanos franceses. A finales del año 1995 manifestaron su rechazo al catecismo de Maastricht y reivindicaron políticas de intervención estatal para corregir los excesos del ultraliberalismo (paro, precarización, pobreza). En Gran Bretaña, la Comisión para la creación de Riqueza y Cohesión social ${ }^{57}$ llegó, de manera pacífica, a parecida conclusión y ha llamado la atención sobre esa vieja idea de que la riqueza es algo más que un crecimiento deducido del PIB. Preocupados seriamente por la cohesión, los miembros de la Comisión manifestaron que un proceso de crecimiento que destruye comunidades, amenaza la ley y el orden y excluye cada vez a más personas, no entrañaba producción de riqueza. De ahí que indicaran la necesidad de actualizar el discurso político en esta época de parados, y sugerían que el contrato que dio lugar al Estado de bienestar debía ser renovado; de lo contrario, sus presagios eran de un porvenir poco halagüeño.

Para hacernos una idea aproximada del proceso al que podríamos estar asistiendo, caso de continuar "progresando" las tendencias en curso, tenemos que ir en busca del tiempo perdido. En este sentido, conviene recordar que el Estado de bienestar apareció en los países europeos durante la postguerra, no sólo como consecuencia del denominado pacto keynesiano, sino gracias a cambios políticos y sociales, ideológicos y económicos, administrativos, financieros e institucionales, sobrevenidos previamente en los diferentes países. Fueron esos cambios, que se desarrollaron durante un largo y complicado proceso, los que hicieron posible que, en un determinado momento histórico, los gobiemos estuvieran preparados para incluir en la agenda politica y ejecutar, con éxito, competencias en materia de política social. Parece como si ahora se tratara de recorrer el proceso en dirección inversa, hasta llegar a desparramar entre asociaciones, empresas, iglesias, fundaciones y organizaciones benéficas, la responsabilidad estatal en políticas de reforma social.

Tan extravagante regresión a la filantropía puede ser percibida, sin duda; como una lamentable muestra —otra más- de la pobreza de nuestra imaginación. A este respecto, y por continuar con las comparaciones, podríamos cotejar las recomendaciones al ahorro y el trabajo, características de los filántropos en la fase de capitalismo salvaje, con las llamadas a la competitividad y autoempleo, que imperan en el presente. Claro que si nuestro antepasados liberales pretendían, con sus consejos moralizadores, eliminar "la caridad humillante" de las iglesias para 
convertir a los trabajadores en mercancía; en el presente, las recomendaciones del neoliberalismo militante persiguen idéntico objetivo aunque, en esta ocasión, a costa de desplazar arraigados derechos sociales de los Estados de bienestar.

Paralelismos tan poco edificantes constituyen una prueba de cómo, en circunstancias distantes, pero vagamente similares, tendemos a dar parecidas respuestas ideológicas e idénticamente erradas. Seguramente el decidido empeño por olvidar el pasado favorezca el que nos despachemos, en tiempos difíciles, con peripecias intelectuales de ese género. En cualquier caso, no dejan de ser inquietantes los retrocesos que están teniendo lugar; por una parte, en el trabajo, con la aparición de la fórmula de trabajo comunitario, -que viene a ser como una forma preburguesa de trabajos forzados- y, por otra, en los sistemas de protección, con la resurrección también de formas preburguesas de asistencia social.

Sobre las virtudes de la actual estrategia filantrópica y sus prédicas moralizantes y voluntaristas, de rancia estirpe en nuestro entorno europeo, poco hay que anadir porque son de todos conocidas. Pero sí es conveniente destacar que se trata de una propuesta defensiva que, en vez de responder a los nuevos problemas que afectan a nuestras sociedades, intenta hacerles frente con un coste mínimo. Por otra parte, el predominio de este curioso planteamiento, -que aborda problemas de comienzos del siglo XXI con remedios propios del siglo XIX-, puede percibirse, no tanto como un producto de las nuevas condiciones sociales y económicas sino, quizá, como una arrogante demostración del poder ilimitado de las actuales élites del capitalismo imperante, o bien, una metáfora sobre la profundidad de nuestra crisis política. Es evidente, en fin, que en estos tiempos de derrumbe del socialismo y de democracia sin política, la opción tiene a su favor el ser, no una fórmula ingenuamente apolítica de intervención privada en la "cuestión social", sino una estrategia deliberadamente despolitizante.

Sobre este último aspecto, y aun a riesgo de señalar lo evidente, resulta obligado desbrozar algunos comentarios. En primer término, produce desconcierto, (y debía generar alguna sospecha), escuchar discursos sobre la sociedad civil, la familia, el voluntariado y el altruísmo, de los mismos actores (individuos o grupos) que emprendieron el ataque, más o menos velado, contra arraigados derechos sociales de los Estados de bienestar. Además, es paradójico, y seguramente algo grotesco, pretender que nos entreguemos a causas fịlantrópicas mientras se nos invita a aceptar, con resignación, políticas que fabrican desempleados y pobres, anatemizan lo público y proclaman la búsqueda de riqueza como el sumo bien. Y, por último, habría que explicar, largo y tendido, el beneficio que esta vieja estrategia, (que podríamos incluir entre los melifluos complementos a la ferocidad del capitalismo de los que ya hablaba Marx), proporciona a los valores supremos de competitividad y eficacia, que son los resortes últimos que impulsan el sistema. Pero lo que a todas luces resulta más inquietante es que los actuales dirigentes y sus asesores, adiestrados en la incapacidad de incluir el sufrimiento de los seres humanos ${ }^{58}$ como un dato que deba tomarse en consideración a la hora de elaborar sus rigurosos análisis económicos, insistan (como en el pasado siglo) en propugnar soluciones éticas a los problemas que sus pragmáticas políticas ocasionan. Parece como si se hubiera llegado a la conclusión siguiente: ya que no es posible integrar a todos los ciudadanos por el trabajo y la economía, y que la influencia benéfica de la disciplina empresarial y patronal disminuye, hay que crear hábitos juiciosos y hacer benevolentes a los ciudadanos acudiendo a las fuerzas impersonales de las ideas. Por consiguiente, la propagación conveniente de una filantropía suave, puede ser una salida apropiada para combatir el desempleo y la indolencia, que acecha a los jóvenes de nuestras sociedades.

En la medida en que esta estrategia filantrópica se reduzca a ser una reacción emocional, de carácter espasmódico y minoritario, y dependiente económica y organizativamente de los gobiernos u organismos internacionales, verá su capacidad seriamente limitada para abordar, con programas eficaces, los graves problemas de este fin de siglo. Es ciertamente arriesgado concebir demasiadas esperanzas sobre el porvenir de esta opción en sociedades en crisis, como las nuestras, alimentadas por el egoísmo colectivo de la riqueza, que aparte de blindarse (para impedir el paso a los emigrantes) ${ }^{59}$, alientan la xenofobia ${ }^{60}$, consienten impávidas el drama del desempleo de sus jóvenes ${ }^{61}$, y en las que el ideal de vivir para el prójimo no es para la mayoría de la población un compromiso atrayente ${ }^{62}$. Todo parece apuntar, más bien, a que la nueva estrategia filantrópica reposa, mayoritariamente, sobre un altruismo epidérmico o débil.

No obstante, es innegable que tiene cierta importancia el que se generalicen actitudes de "altruismo blando" ${ }^{63}$, por dos razones fundamentales. En primer término, porque pueden desempeñar un papel tranquilizador de conciencias de primer orden y, además, porque quizá contribuyan a cubrir de legitimidad el espectáculo de una sociedad preñada de tanta injusticia, pobreza y exclusión.

La estrategia altruista viene contando, en nuestro país, con el apoyo de los "progresistas de clase media" ${ }^{64}$, indiferentes ante el problema del paro de los jóvenes pero muy sensibles ante las legítimas luchas por los problemas de las minorías. Ceñirse sólo a estas luchas progresistas por las minorías nos provee de buena conciencia, es menos peligroso, puede ser más rentable (son temas que cuentan con el apoyo financiero de los gobiernos, nacional y local, y las ONGS), y está de moda.

Al servicio de ese "altruismo relajante" y de la solidaridad del pin's se encuentran, como no podría ser de otra forma, las cadenas televisivas con su empeño inusitado en crear la sensación engañosa de que en nuestras individualistas, hedonistas y 
desmoralizadas sociedades, ese sentimiento generoso es hondo y está mayoritariamente compartido. Haciendo de las desdichas un conmovedor espectáculo, las televisiones compiten con sus programas para hacernos consumir generosidad, a la par que promueven una provechosa reconversión del espectáculo de la exclusión, a los excluidos como espectáculo.

Los llamados medios de comunicación, además de cautivar a dóciles ciudadanos con su patética diversión, y ofrecer gestos humanitarios mezclados con lucrativa publicidad encubierta, priorizan las causas o problemas dignos de atención, estimulan y orientan la generosidad y, en fin, promueven liberadores gestos multitudinarios de solidaridad.
A pesar de tanto prodigio, uno no puede evitar sentir algún desasosiego ante la conjetura de que en nuestras apacibles sociedades del espectáculo, dominadas por un preocupante edarwinismo social. y un inocente egoísmo. ${ }^{65}$, estemos asistiendo a la reconversión de aquella ilustrada inclinación altruista, en lo que podría denominarse "neo-filantropismo televisivo. Sería lastimoso tener que aceptar la hipótesis de que, a la par que vamos amumbando el desprestigiado Estado de bienestar, sean las inefables cadenas televisivas y sus reality shows quienes, con sus intermitentes impulsos altruistas, se encarguen en interés general. de controlar a fondo la Agenda de las políicas sociales. Otro progreso más, sin duda, pero desmoralizador.

\section{Universidad de Castilla-La Mancha, junio de 1998}

1 El entrecomillado corresponde a J.M. KEYNES, Ensayos sobre intervención y liberalismo. Barcelona, 1987.

- Maastricht no impulsó la Europa de los ciudadanos (tesis de Delors), sino que proclamó su fe en la ortodoxia liberal: disciplina presupuestaria (déficit inferior $3 \% \mathrm{PIB}$ y deuda pública $60 \%$ PIB); inflación no mayor en $1,5 \%$, y tipos de interés no más 2 puntos de los tres países con tasa más baja de inflación.

"Ver Comisión de las Comunidades Europeas, Crecimiento, competitividad, empleo. Retos y pistas para entrar en el siglo XXI, Oficina de publicaciones oficiales de las $\mathrm{CO}_{-}$ munidades europeas, Luxemburgo, 1993.

'. Como pretendió Santer, sin éxito, con su propuesta de destinar 280.000 millones de pesetas a la financiación de redes de transporte y pequeñas y medianas empresas. El País, 21 de marzo de 1996.

' La citada cumbre acentó incorporar políticas de empleo sin fondos adicionales. Ver El Pais, 18 de junio de 1997.

" Un resumen del Informe puede consultarse en El Pais, 17 de julio de 1995.

' Ver $A B C, 1$ de julio de 1997.

s El titular pertenece al periódico El Pais, 9 de abril de 1996.

"Al conocerse el espectacular volumen de creación de empleo (350.000 nuevos puestos de trabajo durante el mes de mayo) la Bolsa de Nueva York se desplomó. El País, 8 de junio de 1996

I" Lo que pone de relieve que el modelo de crecimiento realmente existente no se preocupa del emplen. y que la demandada nueva solidaridad no la comparten los que obtienen sus inyıesos de las inversiones. Puede leerse al respecto Libro Blanco, p. 147.

"Ver El Pais, 4 de julio de 1997.

": Lo que contradice la vieja tesis de la dulzura del mercado como un vivero de hábitos y valores preciosos para la convivencia y prosperidad, ahora resucitada. Ver TERMES (Dir.), Libro blanco sobre el papel del Estado en la economia, Madrid, 1996, p. 161.

" Ver El País, lunes 26 de mayo de 1997.

"Sobre estos plantamientos véase P.F. DrUCKER, Administración para el futur, Barcelona, 1993.

1: En Japón las compciones empresariales alientan a las organizaciones mafiosas. De ahi que miles de empresas celebren su junta de accionistas simultáneamente, para evitar chantajes públicos de las mafias. El País, 28 de junio de 1997.

1" Comisión de las Comunidades Europeas, ob cit., p. 153.

$"$ Comisión de las Comunidades Europeas, ob. cit., p. 174.
${ }^{18}$ El denominado Plan Delors para acabar con el paro y recesión cosechó siempre las críticas de los ecofines contrarios a la filosofia del reparto de trabajo, impuesto ecológico y relanzamiento de la inversión. El Pais, 23 de noviembre de 1993.

19 El Consejo Europeo de Florencia que iba a ser la rcumbre del empleos redujo los 2 '4 billones de pesetas del presupuesto comunitario, previstos para crear empleo, a 194.000 millones. El Pais, 22 de junio de 1996.

"' El entrecomillado pertenece al comunicado de la cumbre de los siete paises más ricos celebrada en Denver. Ver El País, 23 de junio de 1997.

"Ver Gosta ESPING-ANDERSEN, Los tres mundos del Estado de bienestar, Valencia, 1994, p. 193.

- J.L. Tortuero Plaza, Aspectos juridicos de las preestaciones: el desempleo y las pensiones. Fundación BBV, 1996. Una muestra puede hallarse en Telefónica. Con el propósito de recortar sus costes (eliminar 20.434 puestos de trabajo hasta el 2001), adelantaba la edad de jubilación de 57 a 55 años. El Pais, miércoles 30 de abril de 1997.

" G. ESPING-ANDERSEN, ob. cit., p. 193.

21 Menos cuando el dinero de los contribuyentes se destina al saneamiento de Bancos. Recuérdese al respecto que, según el gobernador del Banco de España, reflotar Banesto costaba 503.000 millones de pesetas. El Mundo, 3 de enero de 1994.

is Como resalta CasteuLs, a pesar de la ideología de mercados sin trabas, las experiencias de crecimiento económico en las dos últimas décadas están asociadas a restrategias de desarrollo activas por parte del Estado. Ver La Era de la Información: Economia, Sociedad y Cultura, Vol. I, Madrid, 1997, pp. 115 y ss.

3. Libro Blanco, p. 176.

I A medida que se aproximaba la venturosa fecha de la entrada en vigor de la moneda única la obsesión por el déficit fue en aumento. Se quería un euro fuerte, de ahi la propuesta de sanciones para los países que a partir de 1999 no mantengan su déficit por debajo del 3\%. Sobre el polémico Pacto de Estabilidad propuesto por Alemania. El Mundo, 13 de diciembre de 1996.

* La propuesta de un impuesto verde comunitario cuenta con la oposición de las multinacionales del petroleo, más Inglaterra y paises atrasados como España, Grecia, Irlanda y Portugal. El Mundo, 23 de octubre de 1995.

*) Ver el espléndido libro del desencantado N. GLAzER, Los limites de la política social. Madrid, 1992.

" Sobre los ataques neoliberales al Estado de bienestar R. MISHRA, El Estado de bienestar en crisis, 1992, p. 215.

"1. La OIT señala en sus informes discrepantes que no existe evidencia de que el trabajo considerado dentro del crecimiento haya disminuido, y que no han encontrado ninguna evidencia de un crecimiento sin empleon. 
$32^{\circ}$ Un clarificador análisis sobre su significado, N. JOHNSON, El Estado de bienestar en transición, Madrid, 1990.

"2 TOURAINE la caracteriza por la proclamación de una serie de principios excelentes (derechos del hombre, elecciones libres, libertad de espresión, etc.) y, al mismo tiempo la idea de que no.podemos hacer gran cosa 0 , más sencillamente, nada. Ver su obra Critica de la Modernidad, Madrid, 1993.

"Consultar M y R. FruEDMAN, Libertad de elegir, Barcelona, 1980.

3 En este sentido pueden resultar elocuentes las frases del libro de TERMES: •mientras los bienes privados proporcionados públicamente padecen hipertrofia, los bienes públicos (propiedad, seguridad, libertad) se hallan abandonados, ob cit., p. 211.

( "Ver las interesantes reflexiones contenidas en P. ABrhamson; Regimenes europeos del bienestar y políticas sociales europeas ¿Convergencia de solidaridades?., en el libro de S. SARASA y L. MORENo (Comps.): El Estado del bienestar en la Europa del Sur, Madrid, 1995, p. 127.

17. Al respecto puede consultarse con provecho la obra de N. GLAZER, Los limites de la politica social. Madrid, 1992.

Las expresiones entrecomilladas pertenece a N. GLAZER, op. cit.

3. . Tenemos al alcance de la mano la promesa de una Norteamérica renovada. Podemos encontrar ... un sentido a la vida sirviendo a una causa más noble que nosotros mismos, una causa esclarecedora, la iluminación de un millar de luces .... G. Bush, Discurso del Estado de la Unión, 1991. La imagen está tomada de Mateo V:16: -Que vuestra luz brille ante los hombres para que viendo vuestras buenas acciones rindan gloria a vuéstro Padre.

"No deja de ser inquietante que agresivas empresas multinacionales de bebidas refrescantes y hamburguesas, con cifras de negocios mareantes, aporten, a cambio de la publicidad encubierta que obtienen, 18 millones de dólares, frente a los 116 millones de los ciudadanos. Ver El País, 6 de mayo de 1997.

11 Noticia sobre la ċumbre puede leerse en El País, martes 6 de mayo de 1997.

*2. Ver, al respecto, C. Hitchens, Ia madre Teresa una santidad mediática, Le Monde diplomatique, noviembre de 1996.

43. Después de sesenta y un-años, Clinton acabó con la ley que establecía la obligación del Gobierno federal de proteger a los pobres. El ahomo de esta legislación republicana es, en cinco años, 55.000 millones de dólares. El Pais, 23 de agosto de 1996.

$"$ Loï J.D. WacQuavt, El ascenso del Estado penal en Estados Unidos, El País, miércoles 5 de marzo de 1997.

15. F. CASAS, sa reacción y nosotros, en Revista de Servicios Sociales y Politica Social, n. ${ }^{6} 31 / 32,1993$.

* La Cumbre de Río de Janeiro de 1992, al consagrar el concepto adesarrollo sostenible, defendia el principio que el actual progreso económico no puede poner en peligro el porvenir de fururas generaciones.

i Según información aparecida en El País, 19 de junio de 1997, la reforma prevista del Tratado de Maastricht en la cumbre de Amsterdam para conseguir mayor integración políica, más democracia y preparar la ampliación ha fracasado.

15 Durante las últimas elecciones francesas se dijo: "Ahora diríamos no a Europa" (Manuel Valls, encargado de la campaña del vencedor Jospin), y el pecado mayor es el olvido de lo social para pensar sólo en lo económico y, más aún en lo monetario. (frase atribuida al europeísta M. Rocard).

49 Sobre este escándalo moral y las teorías hipócritas X. RUBERT DE VENTÓs, № les des pescado, dales caña, El Pais, 25 dé junio de 1997.

"La teońa de que la introducción de la competencia contribuye de suyo a una mejor calidad de las prestaciones del beneficiàrio o asegurado admite muchas pruebas en contrario. E. Chamorand, Le Système de sainté américain, Paris, 1996.

"En un acto de solidaridad. con los mendigos que deseaban volver a sus casas, el alcalde de Las Palmas embarcó en avión a cuarenta indigentes con destino a la península. Sobre la llamada operación Añoranza, ver El País, 22 de septiembre de 1996.

:2 ABRHAMSOM, op. cit., p. 139

: Consúltese ABrhamsom, op. cit., p. 142.

"Que para garantizar un euro fuerte compromete a mantener el déficit público pór debajo del 3\% del PIB, lo que hace peligrar el mantenimiento en un futuro (2025) de las pensiones. P. SCHWARTZ, ePensiones: pintar como querer, El País, 28 de junio de 1997.

3. Experiencias reaccionarias de este género no carecen de románticos precedentes. Si sustituimos libre mercado por el trono y el altar, se podría comparar este proyecto con el de Restauración Monárquica, que impulsaron las potencias europeas, firmantes de la Santa Alianza después de la derrota de Napoleón.

*6 El entrecomillado es expresión de M. Thatcher.

"El profesor R. Dahrendorf, miembro de la Comisión, esbozaba un resumen del planteamiento en su arículo .Una sociedad sedienta de cambios, El Mundo, 11 de septiembre 1995.

i Con motivo de la presentación de Informe sobre la Salud en el mundo, Hiroshi Nakajima, director de la OMS, afirmaba que el neoliberalismo era un modelo que degradaba las condiciones de salud y añadió: El neoliberalismo no toma en cuenta el sufrimiento de la sociedad, El Pais, lunes 5 de mayo de 1997.

5) Sobre la espera a la puerta de Europa de los inmigrantes ilegales, El Pais, 24 de febrero de 1997; y sobre la práctica de expulsiones El Mundo, 27 de febrero de 1997.

(1) Como botón de muestra la frase de Le Pen: Si falta trabajo, que sean los inmigrantes los primeros despedidos. Ver información en El Mundo, 22 de febrero de 1997.

it Nuestro pais viene contando con el índice de paro entre jóvenes, de 18 a 25, años más alto de Europa. Superior al 40\%.

:2 Según el Informe sobre las organizaciones del voluntariado en España, de diciembre de 1997, del millón largo de voluntarios, el $57 \%$ tienen edades comprendidas entre 18 y 29 años; del total de voluntarios tienen trabajo remunerado el $31 \%$.

(3) De lo contrario, el Ministerio de Trabajo y Asuntos Socialès no hubiera gastado .750 millones en promover la participación en solidaridad, a través del plan estatal del voluntariado.

(i) La crítica nos la hace James Petras en Padres e hijos: dos generaciones de trabajadores españoles. Ajoblanco Especial, verano 1996.

6i Gilles LIPOVETSKY, El creprisculo del deber. Baricelona, 1993. 